Western University

Scholarship@Western

Brain and Mind Institute Researchers'

Publications

Brain and Mind Institute

7-1-2014

\title{
Continuous executive function disruption interferes with application of an information integration categorization strategy.
}

\author{
Sarah J Miles \\ Department of Psychology, The University of Western Ontario, London, ON N6A 5C2, Canada \& \\ Department of Psychology, The University of Western Ontario, London, ON N62 5C2, Canada, \\ sarahmiles5@gmail.com \\ Kazunaga Matsuki \\ Department of Psychology, The University of Western Ontario, London, ON N6A 5C2, Canada \\ John Paul Minda \\ Department of Psychology, The University of Western Ontario, London, ON N6A 5C2, Canada
}

Follow this and additional works at: https://ir.lib.uwo.ca/brainpub

Part of the Neurosciences Commons, and the Psychology Commons

\section{Citation of this paper:}

Miles, Sarah J; Matsuki, Kazunaga; and Minda, John Paul, "Continuous executive function disruption interferes with application of an information integration categorization strategy." (2014). Brain and Mind Institute Researchers' Publications. 292.

https://ir.lib.uwo.ca/brainpub/292 


\title{
Continuous executive function disruption interferes with application of an information integration categorization strategy
}

\author{
Sarah J. Miles • Kazunaga Matsuki • John Paul Minda
}

Published online: 10 April 2014

(C) Psychonomic Society, Inc. 2014

\begin{abstract}
Category learning is often characterized as being supported by two separate learning systems. A verbal system learns rule-defined (RD) categories that can be described using a verbal rule and relies on executive functions (EFs) to learn via hypothesis testing. A nonverbal system learns nonrule-defined (NRD) categories that cannot be described by a verbal rule and uses automatic, procedural learning. The verbal system is dominant in that adults tend to use it during initial learning but may switch to the nonverbal system when the verbal system is unsuccessful. The nonverbal system has traditionally been thought to operate independently of EFs, but recent studies suggest that EFs may play a role in the nonverbal system - specifically, to facilitate the transition away from the verbal system. Accordingly, continuously interfering with EFs during the categorization process, so that EFs are never fully available to facilitate the transition, may be more detrimental to the nonverbal system than is temporary EF interference. Participants learned an NRD or an RD category while EFs were untaxed, taxed temporarily, or taxed continuously. When EFs were continuously taxed during NRD categorization, participants were less likely to use a nonverbal categorization strategy than when EFs were temporarily taxed, suggesting that when EFs were unavailable, the transition to the nonverbal system was hindered. For the verbal system, temporary and continuous interference had similar effects on categorization performance and on strategy use, illustrating that EFs play an important but different role in each of the category-learning systems.
\end{abstract}

S. J. Miles $\cdot$ K. Matsuki $\cdot$ J. P. Minda

Department of Psychology, The University of Western Ontario,

London, ON N6A 5C2, Canada

S. J. Miles $(\bowtie)$

Department of Psychology, The University of Western Ontario, London, ON N62 5C2, Canada

e-mail: sarahmiles5@gmail.com
Keywords Categorization - Attention and executive control · Attention in learning

Making sense of the environment is a major computational challenge faced by all living organisms. Categorization offers one mechanism for decreasing the computational load by treating novel objects according to past experience with similar category members, rather than as objects for which little is known. Given that categorization is an essential cognitive capacity, and given the diversity in objects that must be categorized, it is adaptive to have multiple cognitive systems to carry out this complex task. Although there is some disagreement (e.g., Newell, Dunn, \& Kalish, 2011), a body of research on the cognitive processes used during category learning has provided some evidence that there are at least two separate category-learning systems (Ashby \& Maddox, 2005; Ashby \& O'Brien, 2005; Ashby \& Valentin, 2005; Minda \& Miles, 2010; Nomura \& Reber 2008). In the following article, we build on the assumption that there are multiple category-learning systems in order to investigate the interaction between these systems.

A verbal category-learning system is used to place objects into categories for which there is a verbal rule (i.e., ruledefined, or RD, categories). For example, brass instruments may be placed into the brass category because they produce sound through lip vibration. A person learning to differentiate between brass and other types of instruments would need to learn which dimension to base the categorization rule upon. $\mathrm{He}$ or she may begin by placing all instruments with buttons into the category but receive feedback that some buttoned instruments do not belong to the category (e.g., clarinets) and other nonbuttoned instruments do (e.g., the trombone). Next, he or she may test the rule that all instruments made of brass go in the category but receive feedback that some brass instruments do not (e.g., the saxophone) and other nonbrass 
instruments do (e.g., some brass instruments are made of nickel silver). Finally, he or she may notice that all instruments that have fallen into the brass category are played using lip vibrations.

This process of learning to categorize instruments using the verbal system relies on hypothesis testing: The learner generates a plausible rule, attends to the relevant dimension(s) and ignores the irrelevant dimensions, processes feedback, generates a new rule that has not already been tested, switches attention to a new relevant dimension, and ignores information from dimension(s) that have been previously tested but proven irrelevant. Verbal working memory is important for storing the current and previous rules, and executive functions are important for making the transition from an old to a new rule, ensuring that the contents of working memory reflect the new rule, and ignoring dimensions that have previously been attended to.

However, not all categorization is carried out according to verbal rules. For example, the musical instruments also could have been categorized using the nonverbal category-learning system. A person learning to differentiate between instruments could do so on the basis of overall similarity. He or she could learn that some instruments tend to be made of brass (although some are not), have valves (although some do not), are made of coiled tubes, and make a "brassy" sound. Using the nonverbal system, any instrument that has most of these features would be placed together in a category, while instruments with few or none of these features would not be placed in the category.

The process of learning to categorize objects using the nonverbal system is based on overall similarity to other category members, rather than strict rules, and is often used for non-rule-defined (NRD) categories for which no categorization rule exists or when information from many dimensions is combined before a categorization decision can be made. The nonverbal system operates using relatively basic cognitive processes. Feedback is processed automatically (Maddox, Ashby, Ing, \& Pickering, 2004; Maddox, Love, Glass, \& Filoteo, 2008; Zeithamova \& Maddox, 2007), and categorization responses are computed using procedural learning (Ashby, Maddox, \& Bohil, 2002; Maddox, Bohil, \& Ing, 2004), which is thought to be based on dopaminemediated learning (Maddox, Ashby, \& Bohil, 2003; Maddox \& Ing, 2005). Once the nonverbal system is engaged, it may not have much need for verbal working memory or executive functions.

\section{Executive functions and the interactions between category-learning systems}

The verbal system is thought to be the dominant categorylearning system, in that normally functioning adults tend to initially approach the task of learning categories by attempting to learn classification rules but may switch to the nonverbal system when it is clear that no acceptable rule exists. Strong evidence for this verbal system dominance comes from research featuring mathematical models that can determine a participant's categorization strategy and, therefore, which categorization system is likely to be engaged (Ashby \& Gott, 1988). Even for an NRD category set for which no simple categorization rule exists, participants tend to use a rule-based strategy early in learning but switch to a non-rule-based strategy as learning progresses (e.g., Maddox, Filoteo, Hejl, \& Ing, 2004; Markman, Maddox, \& Worthy, 2006; Worthy, Maddox, \& Markman, 2009). In addition, in a task in which RD categorization is required on some trials and NRD categorization is required on other trials, participants have difficulty switching between categorization strategies and, instead, tend to use an RD strategy for all trials (Ashby \& Crossley, 2010; but see also Erickson, 2008). In short, these findings illustrate that the verbal system is the default and use of the nonverbal system necessitates transferring control from the verbal system.

Executive functions are cognitive abilities used to guide effortful behavior and are related to working memory (Miyake, Friedman, Emerson, Witzki, \& Howerter, 2000), intelligence (Friedman et al., 2006), and performance on real-world tasks (Lamberts, Evans, \& Spikman, 2010). The verbal system has traditionally been thought to rely on executive functions to carry out hypothesis testing. Since the nonverbal system does not engage in hypothesis testing, this system has traditionally been thought to operate independently of executive functions (Ashby, Alfonso-Reese, Turken, \& Waldron, 1998; Minda \& Miles, 2010). For example, secondary concurrent tasks that tax executive functioning interfere more with RD than with NRD category learning (Filoteo, Lauritzen, \& Maddox, 2010; Miles \& Minda, 2011; Minda, Desroches, \& Church, 2008; Waldron \& Ashby, 2001; Zeithamova \& Maddox, 2006), suggesting that executive functions are more important for the operation of the verbal than the nonverbal system. Similarly, secondary tasks during categorization feedback interfere with $\mathrm{RD}$, but not NRD, learning because executive functions are required for feedback processing by the verbal system (Maddox et al., 2004; Zeithamova \& Maddox, 2007). Together, these studies illustrate that executive functions are used by the verbal system during categorization decisions and feedback processing. In addition, areas of the prefrontal cortex are more active during fMRI runs on which an RD strategy was applied, as compared with when an NRD strategy was applied (Nomura \& Reber, 2008). This demonstrates greater recruitment of executive functions for successful RD than for NRD categorization, again supporting the view that executive functions are more important for RD than for NRD learning.

Although the nonverbal system does not seem to rely on executive functions to make categorization decisions or 
process feedback, it may not be the case that the nonverbal system operates totally independently of executive functions. Given that the verbal system is dominant, it may be that executive functions are important for transitioning from the verbal system and engaging the nonverbal system. In contrast to the research discussed above, a series of recent studies has suggested that executive functions may, in fact, be important for the operation of the nonverbal system. Participants with frontal lobe damage (Schnyer et al., 2009), older adults Maddox, Pacheco, Reeves, Zhu, \& Schnyer, 2010), children Huang-Pollock, Maddox, \& Karalunas, 2011), and sleepdeprived adults (Maddox et al., 2009) learned RD and NRD categories. In all cases, it was expected that these groups of participants would show low RD performance, relative to controls, because they all have decreased executive functioning abilities (Buckner, 2004; Bunge \& Zelazo, 2006; Casey, Giedd, \& Thomas, 2000; Fisk \& Sharp, 2004; Harrison, Horne, \& Rothwell, 2000; Nilsson et al., 2005). Of most interest was whether they would also show decreases in NRD performance, suggesting that executive functions are, in fact, used in nonverbal category learning. Indeed, all groups of participants were worse than controls at learning both $\mathrm{RD}$ and NRD categories. Mathematical modeling of their categorization strategies illustrates that these groups tended to use an inappropriate RD strategy to solve the NRD category set, suggesting difficulty making the transition away from the dominant verbal system. In addition, the tendency to use an NRD strategy to solve the NRD category was often positively related to executive functioning abilities (Maddox et al., 2010; Schnyer et al, 2009). Similarly, participants with low working memory capacity took longer to learn an NRD category and were less likely to transition to the appropriate categorization strategy than were participants with high working memory capacity (Decaro, Carlson, Thomas, \& Beilock, 2009). These findings all suggest that executive functions have some role to play in nonverbal category learning, because NRD performance decreased along with executive functions.

\section{Timing of executive function disruption}

Past research has clearly established the importance of executive functions for the verbal system, but as we have discussed, there is a discrepancy in past research on the importance of executive functions in the nonverbal system; experiments using concurrent tasks and fMRI suggest little or no role for executive functions in the nonverbal system, while research on patients with frontal lobe damage, older adults, sleep-deprived adults, and children suggests that executive functions mediate the transition to the nonverbal system. We propose that one way to reconcile the inconsistencies in past research on executive function in the nonverbal system is to consider the timing of the executive function disruptions.
Experiments that have shown that executive functions do not affect NRD categorization have generally relied on concurrent or sequential tasks to tax executive functions while the categorization decision was being made or during feedback processing (e.g., Filoteo et al., 2010; Maddox et al., 2004; Miles \& Minda, 2011; Minda et al., 2008; Waldron \& Ashby, 2001; Zeithamova \& Maddox, 2006, 2007). In both cases, this disruption was temporary, in that executive functions were taxed during the trial but were available in between trials. In contrast, studies showing that executive functions do affect NRD performance have tended to use continuous disruptions to executive functions; children, older adults, people with frontal lobe damage, and people with sleep deprivation have persistent executive functioning deficits that last across the entire categorization task, and these groups show decrements in both types of categorization (Huang-Pollock et al., 2011; Maddox et al., 2009; Maddox et al., 2010; Schnyer et al., 2009). Perhaps, then, this continuous executive functioning interference undermines the ability to transition from the verbal to the nonverbal system, but temporary interference does not.

This is a reasonable hypothesis given the differential role of executive functioning in verbal and nonverbal categorization. For the verbal system, executive functions are important for storing and manipulating information over a short period (e.g., the response that was just made) and over a long period (e.g., rules that have already been tested). Therefore, temporary and continuous interference with executive functioning should hinder learning. For the nonverbal system, executive functioning is hypothesized to be important for engaging the system, rather than for the decision process on a trial-by-trial basis (e.g., storing a rule, processing feedback). Because the transition between systems takes place gradually over a long period of time, continuous disruptions to executive functions may hinder the transition to a greater extent than do temporary disruptions.

\section{The present study}

The present study compared the effects of a temporary executive function disruption with a continuous executive function disruption for the verbal and nonverbal systems. A concurrent task methodology, based on Waldron and Ashby (2001), Zeithamova and Maddox (2006), and Miles and Minda (2011), was used. Participants learned either an RD or an NRD category set under a control, temporary concurrent task, or continuous concurrent task condition. As is illustrated in Fig. 1, participants in the control condition categorized and received feedback on each trial. In the temporary condition, each trial began with two digits that varied in physical size and value. Participants remembered these digits throughout categorization and feedback and then were prompted to report the side of the screen on which the digit with the largest value or the largest size had appeared. Following a blank intertrial 
interval, a new trial began. This task was designed to interfere with executive functioning because, on the majority of trials, the digit with the largest value had the smallest size. Past studies have shown that this task causes poor performance by the verbal system (Miles \& Minda, 2011; Waldron \& Ashby, 2001; Zeithamova \& Maddox, 2006). The continuous condition was the same as the temporary condition, except that the new set of to-be-remembered digits was presented immediately following the memory probe for the previous set of digits (i.e., before the intertrial interval). In this condition, participants always had a set of digits to remember, so that executive functions were continuously taxed.

If executive functions are important for making the transition to the nonverbal system, it would be important for executive functions to be available at some point during the NRD learning process, but the availability of executive functions during each categorization trial may not be necessary for operation of the nonverbal system. If this is the case, a task that temporarily taxes executive functions may not affect engagement of the nonverbal system, but a task that continuously taxes executive functions may interfere with the transition to the nonverbal system. Similar to many other studies that have investigated the transition between categorization systems (Huang-Pollock et al., 2011; Maddox et al., 2009, 2010; Schnyer et al., 2009), the strongest test of our hypothesis was whether categorization strategy differed among conditions. Specifically, participants who learned the NRD category in the continuous condition were expected to be less likely to use an appropriate, nonverbal strategy, because executive functions were not available to facilitate the transition away from an inappropriate, verbal strategy. However, this decrease in appropriate strategy use may not be reflected in categorization performance, because it is possible for an inappropriate verbal strategy to produce moderate performance on an NRD categorization task (Maddox et al., 2010).

Past research has shown that executive functions are important for each categorization decision by the verbal system (e.g., Miles \& Minda, 2011; Waldron \& Ashby, 2001; Zeithamova \& Maddox, 2006), so the tendency to adopt the appropriate verbal strategy and RD categorization performance were expected to be worse in the temporary and continuous conditions than in the control condition. We do not have strong predictions regarding whether temporary and continuous conditions will differ in terms of strategy use and categorization performance for the RD category. Given that the amount of information to be processed was roughly held constant across concurrent task conditions, it may be the case that performance and strategy use in these conditions would not differ. On the other hand, the continuous condition may cause a greater decrement than the temporary condition if the verbal system uses executive functions between trials for tasks such as monitoring performance and switching between rules.

\section{Method}

Participants

Participants included 145 adults from the University of Western Ontario who participated for $\$ 10$ or for course credit. Data from 5 participants were discarded because they did not finish the experiment, data from 2 participants were discarded because they performed at chance for both the categorization and concurrent tasks, and data from 1 participant were discarded because she responded A for the final two blocks, leaving 137 adults ( 107 women, 30 men), with a mean age of 20.27 years $(S D=4.46){ }^{1}$

\section{Materials}

Participants learned to classify sine-wave gratings (pictured in Fig. 2) that varied in spatial frequency and spatial orientation. The categorization rule for the RD category set was based on frequency, such that gratings with few lines went into Category A and gratings with many lines went into Category B. In Fig. 2a, the vertical line separating Category A and Category B, known as the decision bound, represents the strategy that maximizes categorization accuracy (Ashby \& Gott, 1988). The NRD category (Fig 2b) was an information integration (II) category in which frequency and orientation information need to be integrated before the categorization decision can be made. The decision bound in Fig. $2 b$ can be expressed as "if the lines in the grating have a smaller orientation than frequency, the grating goes in Category A; otherwise, it goes in Category B." However, this is not a practical categorization rule, because frequency and orientation are not directly comparable; instead, this category is thought to be learned nonverbally.

For the RD category set, 80 stimuli were generated (Ashby \& Gott, 1988), with 40 in Category A and 40 in Category B. The distribution of each category was specified by a mean and variance for frequency and orientation and a covariance between them, shown in Table 1. Stimuli for each category were generated by randomly sampling 40 coordinates from the appropriate multivariate normal distribution and using the grt package in R (R Core Team, 2012) to generate a sine wave grating corresponding to each coordinate. Sine wave grating frequency was calculated as $f=.25+\left(x_{f} / 50\right)$ cycles per gradient, and orientation was calculated as $o=x_{o} \times(\pi / 500)$ radians. Each stimulus was $370 \times 370$ pixels. Stimuli for the II category set were generated in the same way, except that different parameter values were used (Table 1). The resulting category structures for RD and II category sets are illustrated in Fig. 2a, b. All participants learned to categorize the same 80

\footnotetext{
${ }^{1}$ The same pattern of results was found when all participants who finished the study were included in the analyses.
} 


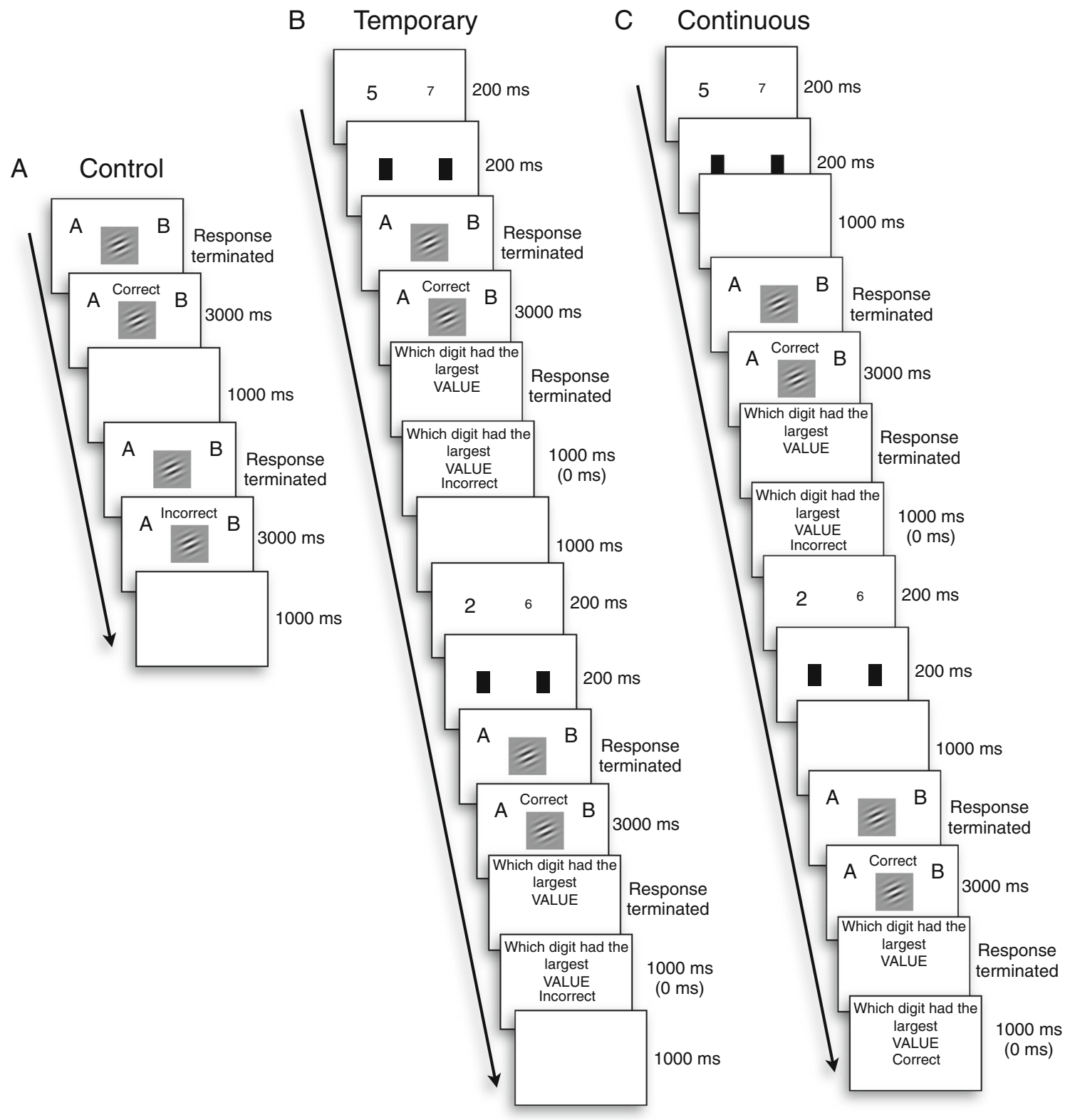

Fig. 1 Task design for the first 10 trials, with timing for trials 11-320 given in parentheses. a Control condition. b Temporary condition. c Continuous condition. Note that the temporary and continuous conditions

RD or II stimuli. Stimulus parameters and generation were the same as those used by Zeithamova and Maddox (2006) and Miles and Minda (2011).

Procedure

Participants learned either the RD or the II category set in the control, temporary, or continuous condition. The number of participants in each condition is listed in Table 2. The learning stage for each category set consisted of four blocks of 80 trials. The order of the 80 stimuli was randomly generated on each block for each participant. Following the categorization task, are the same, except that the intertrial interval was before the presentation of the digits in the temporary condition and after the presentation of the digits in the continuous condition

participants typed a description of the categorization strategy they used on the final trial.

On each categorization trial of the control condition (see Fig. 1a), participants saw a single sine-wave grating and assigned it to either Category $\mathrm{A}$ or Category B by pushing the button labeled $A$ (1 key) or $B(0$ key $)$, respectively, on a standard computer keyboard. The word Correct was displayed for a correct categorization or the word Incorrect was displayed for an incorrect categorization in black font for 3,000 ms, followed by a 1,000-ms blank screen. The categorization stimulus remained on the screen throughout categorization and feedback. 

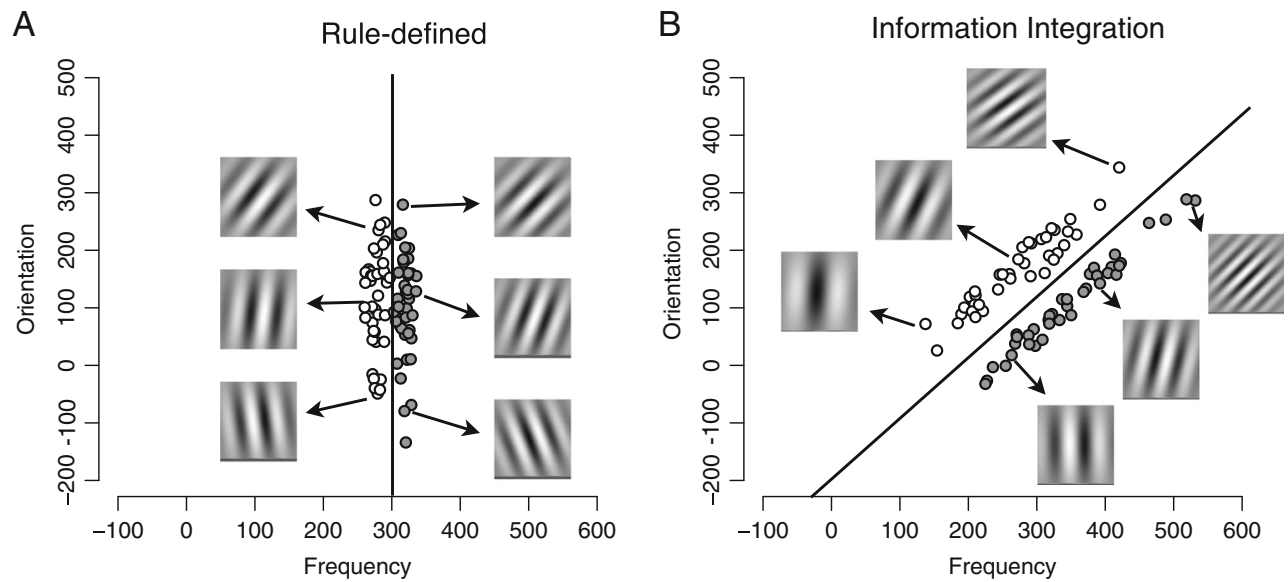

Fig. 2 a Category structure for the rule-defined category set. Each light circle represents a stimulus from Category A, and each dark circle represents a stimulus from Category B. b Information Integration category structure. This is a non-rule-defined category

On each trial of the temporary condition (see Fig. 1b), participants completed an executive function task, similar to that used by Waldron and Ashby (2001) and Miles and Minda (2011), concurrent with the categorization task. At the beginning of each trial, two digits were flashed to the left and the right of the screen, followed by a black rectangular mask. The digits varied in numerical value (between two and eight) and in physical size (90 or 180 pixels). The value and size of the digits were assigned so that on $85 \%$ of the trials, the numerically largest digit was physically smallest. On the remaining $15 \%$ of the trials, the numerically largest digit was also physically largest. Participants were to remember the size and value of each digit throughout the trial. Next, in the categorization stage of the trial, participants categorized sine-wave gratings and received feedback as described in the control condition. In the final stage of the trial, the question "Which digit had the largest value?" or "Which digit had the largest size?" appeared on the screen, and participants indicated their response by pressing the button labeled Left (Q key) or Right (O key). For example, if a large 5 appeared on the left side of the screen and a small 7 appeared on the right side of the screen, followed by the question "Which digit had the largest size?" the correct response was Left. Feedback on the concurrent task was given by presenting the word Correct or Incorrect in black, followed by an intertrial interval. After the tenth trial, the word

Table 1 Distribution parameters for rule-defined and information integration category sets

\begin{tabular}{lccccc}
\hline Category Structure & $\mu_{f}$ & $\mu_{o}$ & $\sigma_{f}^{2}$ & $\sigma_{o}^{2}$ & $\operatorname{cov}_{f}, o$ \\
\hline $\begin{array}{l}\text { Rule-defined } \\
\quad \text { Category A }\end{array}$ & 280 & 125 & 75 & 9,000 & 0 \\
$\quad$ Category B & 320 & 125 & 75 & 9,000 & 0 \\
$\begin{array}{l}\text { Information Integration } \\
\quad \text { Category A }\end{array}$ & 268 & 157 & 4,538 & 4,538 & 4,351 \\
$\quad$ Category B & 332 & 93 & 4,538 & 4,538 & 4,351 \\
\hline
\end{tabular}

Note. $f=$ frequency, $o=$ orientation of the sine wave grating
Value or Size was used to prompt the participant's response for the concurrent task, instead of the entire question, "Which number had the greatest value (size)?" We wanted to ensure that participants remembered the response type that was expected at each stage of the trial, so we embedded instructions within the first 10 trials. However, the presentation of extra verbal information may interfere with working memory and category processing, so the prompting questions were removed once participants were familiarized with the experimental procedures. For similar reasons, feedback was no longer given for the concurrent task after the tenth trial, although feedback remained for the categorization task.

The trials of the continuous condition (see Fig. 1c) were similar to those of the temporary condition, in that participants carried out a executive function task concurrent with categorization. The concurrent task was modified so that the new set of to-be-remembered digits was presented immediately following the memory probe for the previous set of digits (i.e., before the intertrial interval), rather than following the intertrial interval. In this condition, participants always had a set of digits to remember, so that executive functions were taxed during categorization and the intertrial interval.

Table 2 Number of participants, overall categorization performance, and concurrent task performance for each condition

\begin{tabular}{|c|c|c|c|c|c|}
\hline \multirow[b]{2}{*}{ Condition } & \multirow[b]{2}{*}{$n$} & \multicolumn{2}{|c|}{ Categorization } & \multicolumn{2}{|c|}{ Concurrent Task } \\
\hline & & $M$ & $S D$ & $M$ & $S D$ \\
\hline \multicolumn{6}{|c|}{ Information Integration } \\
\hline Control & 23 & .69 & .08 & - & - \\
\hline Temporary & 23 & .62 & .12 & .92 & .06 \\
\hline Continuous & 22 & .61 & .10 & .90 & .09 \\
\hline \multicolumn{6}{|l|}{ Rule Defined } \\
\hline Control & 22 & .79 & .11 & - & - \\
\hline Temporary & 22 & .69 & .18 & .93 & .05 \\
\hline Continuous & 25 & .63 & .16 & .92 & .07 \\
\hline
\end{tabular}


In order to ensure that participants attended to the concurrent task and, therefore, that their executive functions were depleted, participants were instructed that it was necessary to achieve at least $80 \%$ correct on the concurrent task in the temporary and continuous conditions. If a participant's performance on this task fell below $80 \%$, the warning "Your performance on the number task is below $80 \%$. Please do your best to improve your performance." was written on the screen in orange, and feedback was presented in orange, until performance was above $80 \%$.

\section{Results}

Concurrent task performance

Average concurrent task performance was calculated for each condition and category set and is presented in Table 2. Using a 2 (concurrent task) $\times 2$ (category set) completely randomized factorial ANOVA, there was no effect of concurrent task, illustrating that the temporary and continuous tasks were performed equally well and suggesting that these tasks were roughly matched in terms of difficulty, $F(1,88)=1.98, p=$ $.16, \eta^{2}=.02$. There was no effect of category set, such that participants who learned the RD and the II category sets performed equally well on the concurrent tasks, $F(1,88)=$ $0.59, p=.45, \eta^{2}=.01$. There was also no significant interaction between concurrent task and category set, $F(1,88)=0.12$, $p=.73, \eta^{2}=.001$.

None of the participants in the RD-temporary condition, 2 (8\%) in the RD-continuous condition, none in the IItemporary condition, and 4 (18\%) in the II-continuous condition had concurrent task performance below $80 \%$. In all conditions, the participants who performed poorly on the concurrent task also tended to perform poorly on the categorization task. In fact, for all conditions, the correlation between overall categorization performance and concurrent task performance was significant [see Fig. 3; II-temporary, $r(21)=.61$, $p<.001$; II-continuous, $r(20)=.72, p<.001$; RD-temporary, $r(20)=.67, p<.001$; RD-continuous, $\mathrm{r}(23)=.35, p=.04]$, illustrating that those who were least successful at the concurrent task were also least successful at the categorization task, regardless of whether the concurrent task was temporary or continuous and regardless of whether the categorization task used the verbal or nonverbal system.

Typically, in concurrent task experiments, participants who get less than $80 \%$ correct on the concurrent task are not included in the categorization analysis, because it is unclear whether the participant was performing the concurrent task at all and, as a result, it is unclear whether he or she was categorizing with decreased executive functions (e.g., Miles \& Minda, 2011; Waldron \& Ashby, 2001; Zeithamova \& Maddox, 2006). Because concurrent task performance was so strongly correlated with categorization performance in this study, we opted not to use this analysis strategy, because it would mean removing a disproportionate number of nonlearners. In addition, the participants who got less than $80 \%$ correct on the concurrent task were not evenly distributed across conditions. Removing these participants would mean taking more nonlearners out of some conditions than out of others, potentially obscuring the effect of the concurrent tasks. However, a reanalysis of the data excluding those who performed poorly on the concurrent task shows essentially the same pattern of results as we will report.

\section{Categorization strategy}

To investigate the effect of the timing of the executive function disruption on each type of categorization, strategy use was compared across conditions for the RD and II category sets. For the II set, participants in the continuous condition were expected to have difficulty transitioning to the nonverbal system, resulting in decreased use of an appropriate information integration strategy, relative to the control and temporary conditions. Separately for each block of each participant, a number of decision-bound models based on the general recognition theory (GRT) were fit to the participant's pattern of categorization responses (Ashby \& Gott, 1988; Maddox \& Ashby, 1993). According to GRT, a categorization strategy can be represented as a decision boundary that splits multidimensional perceptual space into categories (e.g., Category A, Category B) with associated responses (e.g., push the $A$ key, push the $B$ key). Each stimulus is represented as a point in perceptual space, and the corresponding categorization response is generated by determining the response region into which the stimulus falls (Ashby \& Gott, 1988). Essentially, these models work by comparing the response a participant would have given had they used a particular strategy with the response they actually gave. The model is said to fit the participant's data to the extent that the model's predicted response corresponds with the participant's actual response.

Four classes of strategies were fit to each participant's pattern of responses, separately for each block: (1) strategies based on frequency, (2) a strategy based on orientation, (3) II strategies based on two dimensions, and (4) random responding (i.e., guessing) strategies (see Appendix 1 and Ashby, 1992, for more details). For every participant, at every block, the class of the best-fitting strategy (i.e., the one with the lowest Akaike information criterion $[\mathrm{AIC}]$ ) was noted. For the II category set, II strategies were appropriate, and for the RD category set, frequency strategies were appropriate, because they would result in the best categorization performance.

Figure 4a illustrates the proportion of participants best fit by an appropriate strategy at each block in each condition, separately for the II and RD category sets. For the II category set, strategy use in the continuous condition differed from 

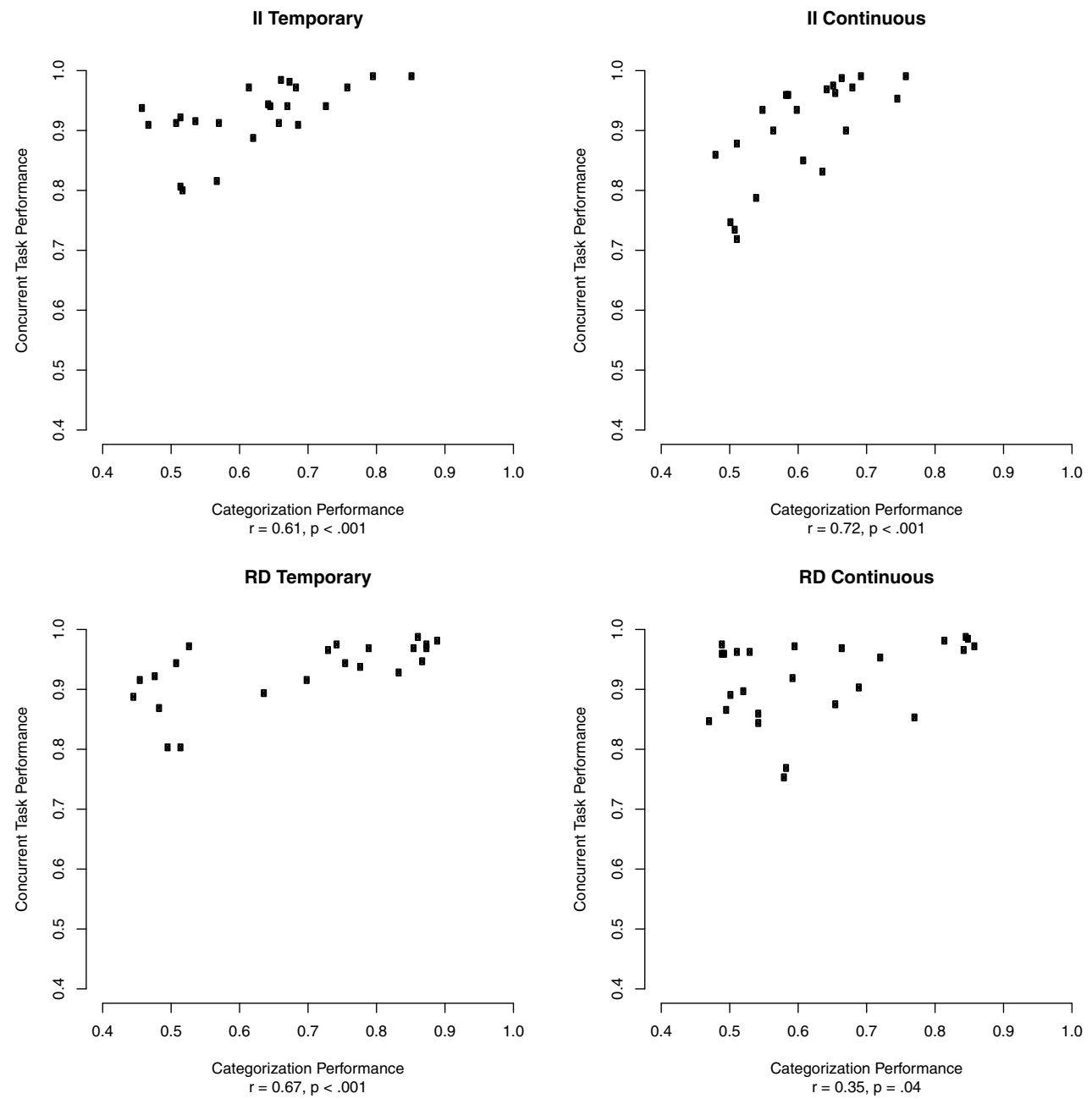

Fig. 3 Correlation between overall categorization performance and overall concurrent task performance for each condition. The $p$ values are one-tailed

those in the control condition and the temporary condition. A 3 (concurrent task) $\times 4$ (block) mixed ANOVA on the proportion of participants using an appropriate II strategy to learn the II set revealed a main effect of block, $F(3,195)=6.29, p<$ $.001, \eta^{2}=.09$. This indicates that participants tended to increase their use of an appropriate strategy as learning progressed, perhaps reflecting a transition to the nonverbal system. There was a marginal effect of condition, $F(2,65)=$ $3.01, p=.056, \eta^{2}=.08$, but no interaction between block and condition, $F(6,195)=0.32, p=.92, \eta^{2}=.01$. Because we were most interested in the effect of the continuous task, planned comparisons were conducted to compare proportion of appropriate strategy use, averaged across blocks, in the continuous condition with that in each of the other conditions. Appropriate strategy use in the continuous condition $(M=.27)$ was significantly less than that in the control condition $(M=$ $.50), F(1,66)=4.68, p=.03, \eta^{2}=.07$. Importantly, appropriate strategy use in the continuous condition was also lower than that in the temporary condition $(M=.49), F(1,66)=4.20$, $p=.044, \eta^{2}=.06$, suggesting that concurrent task type did affect strategy use during II learning. Specifically, participants in the continuous condition were less likely to engage in an appropriate categorization strategy than were participants in the temporary condition. Table 3 indicates the proportion of participants using each class of categorization strategy and shows that participants in the II-continuous condition were more likely to use an inappropriate frequency strategy and more likely to persist with a guessing strategy, as compared with participants in the II-temporary condition. Table 4 in Appendix 2 illustrates mean model fit for participants fit by each model in each condition and illustrates that fit is relatively consistent across models.

In contrast to strategy use for the II set, most participants who learned the RD set in the control condition used an appropriate strategy, but fewer in the temporary and continuous conditions did so, especially early in learning. For the RD category set, a 3 (concurrent task) $\times 4$ (block) mixed ANOVA on the proportion of participants using an appropriate strategy revealed a main effect of block, $F(3,198)=3.15, p=.03, \eta^{2}=$ .05 . There was also a main effect of condition, $F(2,66)=5.97$, $p=.004, \eta^{2}=.15$, but no interaction between block and condition, $F(6,198)=1.63, p=.14, \eta^{2}=.05$. Because we 
A

Information Integration

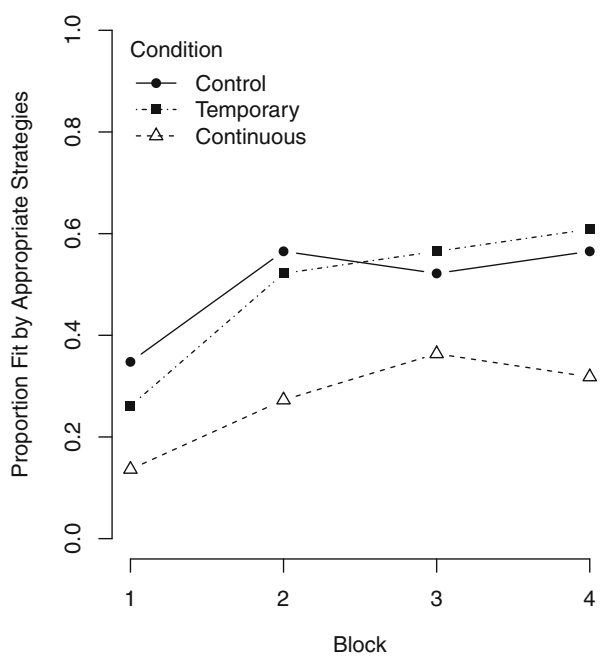

B

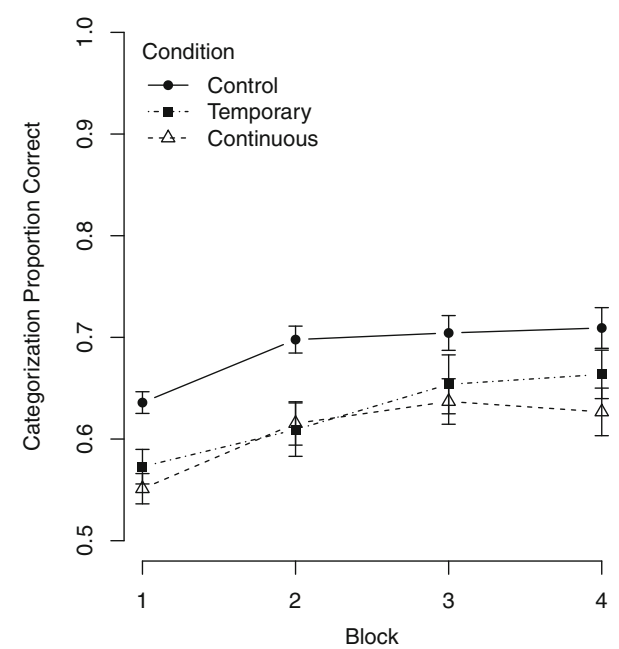

Rule-defined

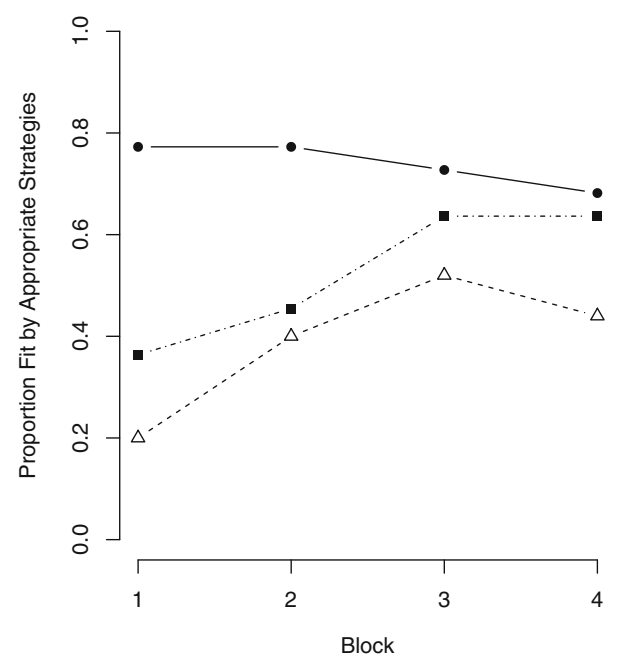

Rule-defined

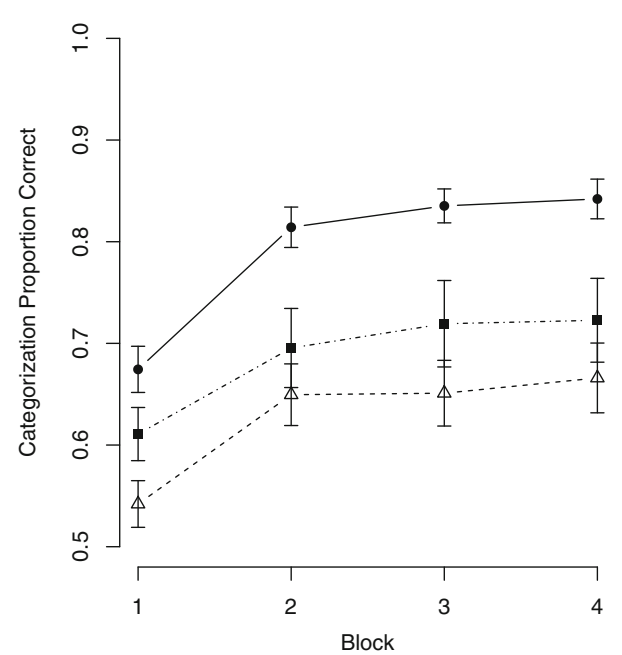

Fig. 4 a Proportion of participants in each condition who were best fit by the appropriate strategy for each category set. b Average proportion correct for each category type and condition. Error bars denote standard errors of the means

were most interested in the effect of the continuous task, planned comparisons were conducted to compare proportion of appropriate strategy use, averaged across blocks, in the continuous condition with that in each of the other conditions. Appropriate strategy use in the continuous condition $(M=.39)$ was significantly lower than that in the control condition $(M=$ $.74), F(1,67)=11.87, p<.001, \eta^{2}=.15$. Although strategy use in the continuous condition was numerically lower than that in the temporary condition $(M=.52)$, this difference was not significant, $F(1,67)=1.79, p=.19, \eta^{2}=.03$, illustrating that concurrent task type did not significantly affect strategy use during RD learning. ${ }^{2}$

\footnotetext{
${ }^{2}$ When the Bayesian information criterion was used instead of the Akaike information criterion, the general pattern of results remained; for the II set, appropriate strategy use was lower in the continuous than in the intermittent condition, and for the RD set, appropriate strategy use did not differ between the continuous and intermittent conditions.
}

\section{Categorization performance}

To further investigate the effect of the timing of the executive function disruption on each type of categorization, performance was compared across conditions for the RD and II category sets. For the II set, the effect of most interest was whether the continuous condition caused a greater decrement than the temporary condition. Although the II task is optimally solved using the nonverbal system, moderate performance (i.e., around $70 \%$ correct) can also be obtained using a verbal strategy based on frequency. Therefore, it was possible that the differential strategy use exhibited in the II-continuous and II-temporary conditions would not be reflected in categorization performance. Consequently, while categorization performance may provide some insight into learning, an absence of a difference between conditions does not necessarily mean that the conditions were learned in similar ways. In addition, tasks similar to the temporary 
Table 3 Proportion of participants in each condition best fit by each categorization strategy across blocks

\begin{tabular}{|c|c|c|c|c|}
\hline \multirow[b]{2}{*}{ Block } & \multicolumn{4}{|l|}{ Strategy } \\
\hline & Information Integration & Frequency & Orientation & Guess \\
\hline & II-Control & & & \\
\hline 1 & .35 & .61 & .00 & .04 \\
\hline 2 & .57 & .43 & .00 & .00 \\
\hline 3 & .52 & .48 & .00 & .00 \\
\hline \multirow[t]{2}{*}{4} & .57 & .43 & .00 & .00 \\
\hline & II-Temporary & & & \\
\hline 1 & .26 & .22 & .04 & .48 \\
\hline 2 & .52 & .17 & .00 & .30 \\
\hline 3 & .57 & .13 & .00 & .30 \\
\hline \multirow[t]{2}{*}{4} & .61 & .26 & .00 & .13 \\
\hline & II-Continuous & & & \\
\hline 1 & .14 & .41 & .14 & .32 \\
\hline 2 & .27 & .36 & .09 & .27 \\
\hline 3 & .36 & .45 & .00 & .18 \\
\hline \multirow[t]{2}{*}{4} & .32 & .36 & .00 & .32 \\
\hline & RD-Control & & & \\
\hline 1 & .09 & .77 & .00 & .14 \\
\hline 2 & .18 & .77 & .00 & .05 \\
\hline 3 & .27 & .73 & .00 & .00 \\
\hline \multirow[t]{2}{*}{4} & .32 & .68 & .00 & .00 \\
\hline & RD-Temporary & & & \\
\hline 1 & .27 & .36 & .00 & .36 \\
\hline 2 & .18 & .45 & .00 & .36 \\
\hline 3 & .05 & .64 & .00 & .32 \\
\hline \multirow[t]{2}{*}{4} & .09 & .64 & .00 & .27 \\
\hline & RD-Continuous & & & \\
\hline 1 & .28 & .20 & .00 & .52 \\
\hline 2 & .28 & .40 & .04 & .28 \\
\hline 3 & .20 & .52 & .04 & .24 \\
\hline 4 & .20 & .44 & .00 & .36 \\
\hline
\end{tabular}

Note. Frequency is the appropriate strategy for the RD category set, and information integration is the appropriate strategy for the II category set

task sometimes interfere with II learning (Zeithamova \& Maddox, 2006) ${ }^{3}$ and sometimes do not (Miles \& Minda, 2011), allowing for the possibility that performance in the II-temporary condition may differ from that in the II-control condition.

Learning curves for each condition, shown in Fig. 4b, were calculated by averaging performance across participants for each block. For the II category set, a 3 (concurrent task) $\times 4$

\footnotetext{
${ }^{3}$ Zeithamova and Maddox (2006) carried out a study using an II category set and a temporary concurrent task very similar to ours and found that temporarily taxing executive functions decreased nonverbal categorization performance by $6 \%$. As in the present study, Zeithamova and Maddox (2006) were not directly interested in whether temporarily taxing executive functions decreased II performance relative to a control condition, so they did not test whether the $6 \%$ drop was a significant one.
}

(block) mixed ANOVA revealed an effect of block, indicating that participants learned across the experiment, $F(3,195)=$ $26.68, p<.001, \eta^{2}=.29$. There was also an effect of concurrent task, $F(2,65)=5.67, p=.005, \eta^{2}=.15$, and no interaction between block and concurrent task, $F(6,195)=0.80, p=.57$, $\eta^{2}=.02$. Because we were most interested in the effect of the continuous task, planned comparisons were conducted to compare overall II performance in the continuous condition with that in each of the other conditions (see Table 2). Overall II performance in the continuous condition was significantly worse than that in the control condition, $F(1,66)=10.24, p=$ $.002, \eta^{2}=.13$, but was no worse than performance in the temporary condition, $F(1,66)=0.37, p=.54, \eta^{2}=.01$. Contrary to the analysis of strategy use, continuously interfering with executive functions was no more detrimental to II performance than was temporarily interfering with executive functions.

For the RD category set, a 3 (concurrent task) $\times 4$ (block) mixed ANOVA revealed an effect of block, $F(3,198)=49.09$, $p<.001, \eta^{2}=.43$. There was also an effect of concurrent task, $F(2,66)=9.45, p<.001, \eta^{2}=.22$, and no interaction between block and concurrent task, $F(6,198)=0.94, p=.47, \eta^{2}=.03$. Planned comparisons of overall RD performance in the continuous condition with that in each of the other conditions (see Table 2) indicated that the continuous condition was significantly worse than the control condition, $F(1,67)=18.61, p<$ $.001, \eta^{2}=.22$. Although performance in the continuous condition was numerically lower than that in the temporary condition, this difference was not significant, $F(1,67)=2.42, p=$ $.13, \eta^{2}=.03$. These results correspond well with the strategy use results, in which participants in the control condition were more likely to use the appropriate strategy than were those in the temporary and continuous conditions.

\section{Categorization performance by strategy type}

Figure 5 illustrates that, regardless of condition, categorization performance was relatively consistent across strategy types. Participants who used the appropriate strategy for the II set tended to perform around $70 \%$ correct, participants who used a frequency strategy tended to perform around $60 \%$ correct, and participants who guessed tended to perform around $50 \%$ correct, regardless of whether they were in the control, temporary, or continuous condition. Similarly, for the RD set, participants tended to perform around $70 \%, 80 \%$, and $50 \%$ correct for II, frequency, and guessing strategies, respectively. This illustrates that differences in categorization performance across conditions were a result of differences in the proportion of participants using a given strategy, rather than differences in the effectiveness of applying the categorization strategies. For example, performance in the II-continuous condition was worse than that in the II-control condition because participants were less likely to use the appropriate II 
strategy (i.e., $32 \%$ of participants used the appropriate strategy in the final block of II-continuous, but $57 \%$ did so in IIcontrol), not because those who used the strategy were less effective at applying it.

Although the II task is optimally solved using the nonverbal system, moderate performance can also be obtained using a verbal strategy. Our modeling results showed that a subset of participants (i.e., about $40 \%$ in the control condition) may have been learning the II category set using the verbal system. For this subset of participants, the addition of a temporary concurrent task would be expected to interfere with the operation of the verbal system and increase the likelihood of using a guessing strategy, consequently decreasing categorization performance. As a result, lower II performance would be expected among participants who did not use an appropriate strategy (i.e., may have been using a verbal strategy) in the temporary condition than among participants who did not use an appropriate strategy in the control condition. To test this hypothesis, final block categorization performance was compared for participants in the II-control and II-temporary conditions who were identified as using an inappropriate (i.e., frequency, orientation, guessing) strategy in the final block. Participants in the temporary condition who used an inappropriate categorization strategy were more likely to use a guessing strategy and, consequently, performed significantly worse in block $4(n=9, M=.57, S D=.08)$ than did participants in the control condition $(n=10, M=.64, S D=.05)$, Welch's $t(13)=2.36, p=.03$. In contrast, there was no difference in block 4 performance between temporary $(n=14, M=.72, S D$ $=.09)$ and control $(n=13, M=.76, S D=.09)$ participants who used an appropriate II strategy, Welch's $t(25)=1.07, p=.29$. This pattern of results is consistent with the hypothesis that the difference in performance between the II-control and IItemporary conditions was partly due to the effect of the concurrent task among the II-temporary participants who were not categorizing the II stimuli using the nonverbal system. The continuous task could similarly decrease the performance of participants using an inappropriate rule but could also decrease performance by hindering the transition to the nonverbal system.

\section{Discussion}

Participants learned to categorize an RD category set, optimally learned by the verbal system, or an II category set, optimally learned by the nonverbal system, while carrying out no concurrent task, a concurrent task that temporarily taxed executive functions, or a concurrent task that continuously taxed executive functions. Given that executive functions are known to be important for the verbal system, we expected that both temporarily and continuously taxing executive functions would interfere with RD learning. Indeed, both concurrent tasks interfered with appropriate strategy use and categorization performance during RD learning. However, regardless of whether executive functions were taxed temporarily or continuously, RD learners were about equally likely to use the appropriate frequency-based strategy and performed equally well, suggesting that the timing of the executive function disruption may not be an important factor for the verbal system.

Past research on the role of executive functions for the nonverbal system is equivocal. Some studies indicate that executive functions may be important for transitioning from the dominant verbal system to the nonverbal system (Decaro, Thomas, Albert, \& Beilock, 2011; Huang-Pollock et al., 2011; Maddox et al., 2009, 2010; Schnyer et al., 2009). Those studies that have found that executive functions are important for the nonverbal system tend to be ones in which executive functions were never fully available throughout the categorylearning process. Therefore, we expected that continuously interfering with executive functions would interfere with the nonverbal system more than would temporarily interfering with executive functions.

Mathematical modeling of participants' strategies provided evidence that information integration learning proceeded differently in the continuous and temporary conditions because the type of categorization strategy a participant tended to use was affected by whether executive function interference was temporary or continuous. Participants in the continuous condition were less likely to use an appropriate II strategy than were participants in the temporary condition. That is, continuously taxing executive functions seemed to interfere with participants' abilities to find and apply the appropriate II strategy. Given that the verbal system is thought to be dominant early in learning, it is possible that continuously taxing executive functions interfered with the transition from the verbal to the nonverbal system. On the other hand, taxing executive functions temporarily still allowed for the access to executive functions that was necessary for the transition between systems, which is one explanation for why strategy use in the temporary condition was similar to that in the control condition. These results suggest that, as predicted, one role for executive functions in the nonverbal system may be to mediate the transition between systems.

Another role for executive functions may be to mediate attention during category learning. Early category learning is often characterized by diffuse attention to stimulus dimensions (Rehder \& Hoffman, 2005). Success at the RD task requires learning to focus attention on the diagnostic stimulus dimension (i.e., frequency), while success at the II task is possible without this type of selective attention. For RD categorization, it is possible that temporary interference with executive functions caused participants to have difficulty selectively attending to the diagnostic dimension, resulting in decreased appropriate strategy use. Because selective 
II Control

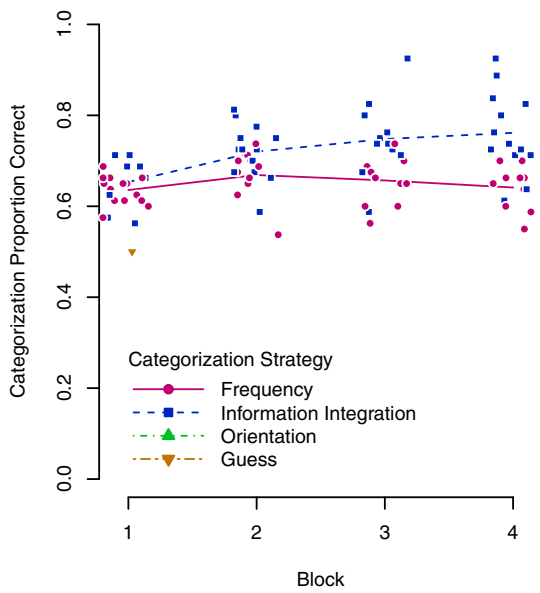

RD Control

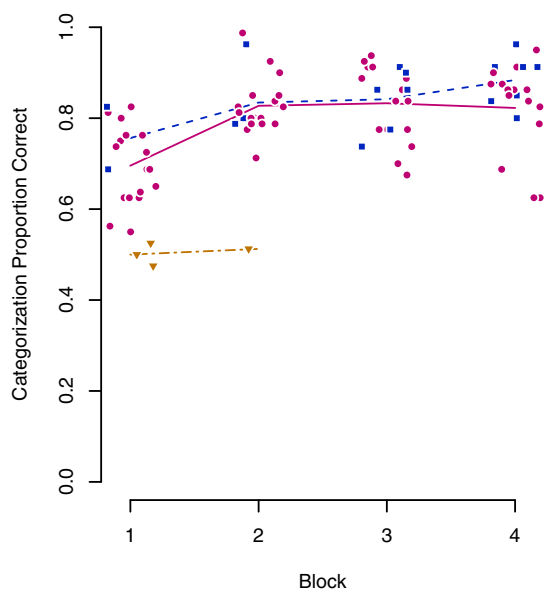

Fig. 5 Categorization performance of participants in each condition best fit by each type of categorization strategy. Each point represents a single participant's categorization performance at a single block, and the symbol indicates the best-fitting categorization strategy. Each line represents
II Temporary

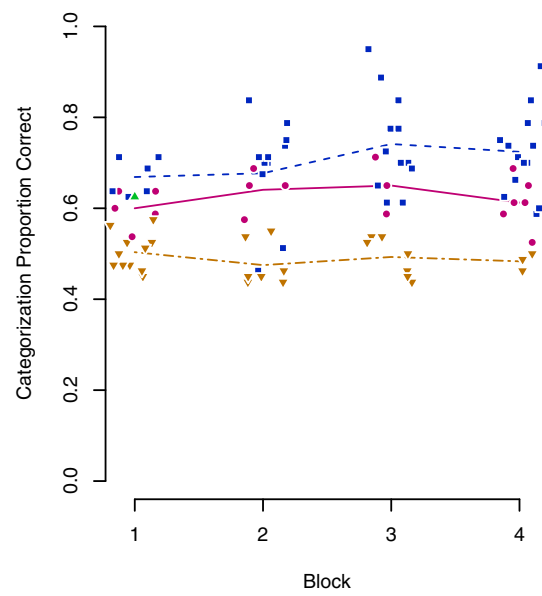

RD Temporary

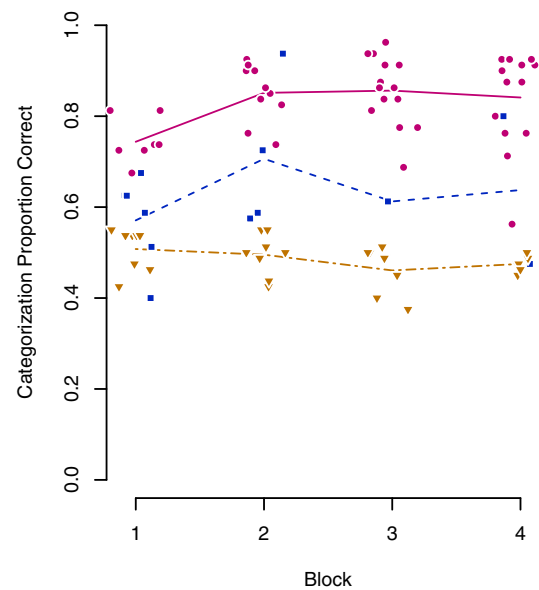

average categorization performance of participants who used a given categorization strategy. Note that incomplete or missing lines occur when no participant was best fit by a particular strategy in a given block. Points have been jittered along the $x$-axis to prevent occlusion attention was not required for II learning, temporary interference with executive functions did not affect strategy use. While this is an interesting explanation of the pattern of strategy use for RD and II category learning while executive functions were temporarily taxed, it does not provide an explanation for our major finding of a decrease in appropriate II strategy use under continuous, as compared with temporary, concurrent task conditions. Under this explanation we would expect that continuously taxing executive functions would have no more of an effect on II strategy use than would temporarily taxing executive functions, because selective attention to a single stimulus dimension is not required in either condition.

It may seem curious that there was no difference in II categorization performance between the continuous and temporary conditions, given that participants in the continuous condition were less likely to use the appropriate strategy than were participants in the temporary condition. This is most likely due to the fact that a person categorizing according to a single dimension (e.g., a frequency strategy) could achieve up to $70 \%$ correct on the II category set. Even among participants who were using the appropriate II strategy, mean final block II performance was only $74 \%$. That is, although participants in the temporary condition were more likely to use the appropriate strategy, they were not necessarily applying the strategy very well, because this strategy is learned gradually over hundreds of trials (Helie, Waldschmidt, \& Ashby, 2010). Therefore, a change in categorization strategy does not necessarily mean a change in categorization performance. Given that we were most interested in the transition between categorization systems, which is reflected by categorization strategy, it is crucial that we found that continuously taxing executive functions hindered the use of an II strategy, 
even if it did not translate to decreased categorization performance, relative to temporarily taxing executive functions.

Temporarily taxing executive functions had a greater effect on nonverbal categorization performance than might have been expected. However, the findings from the present study are not without precedence. Zeithamova and Maddox (2006) carried out a study using an II category set and a temporary concurrent task and found that performance in this condition was $6 \%$ lower than in the control condition. This value is similar to the $7 \%$ decrement found in the present study. These findings may be puzzling in light of the fact that verbal concurrent tasks have typically been predicted not to affect the nonverbal system. Although the II task is optimally solved with the nonverbal system, as has already been discussed, moderate performance can also be obtained using a strategy based on frequency. Our modeling results showed that a subset of participants used a single-dimensional categorization strategy and, therefore, may have been learning the II category set using the verbal system. For this subset of participants, the temporary concurrent task would be expected to interfere with the use of the verbal system, resulting in decreased II categorization performance. Indeed, of the participants learning the II set who were not fit by an II strategy, categorization performance was lower when executive functions were temporarily taxed than when they were not taxed. These results suggest that the concurrent task may have interfered with the verbal system, resulting in poorer II performance among participants who were using the verbal system to learn the II category. This may be one explanation for the decreased II performance when executive functions were taxed temporarily. For this reason, the question of most interest in the present study was whether II performance and strategy use in the continuous condition differed from that in the temporary condition, rather than that in the control condition.

\section{Concurrent task difficulty}

Although the continuous task was designed so that executive functions were always taxed, it was not necessarily any more difficult than the temporary task. The tasks were designed to be roughly equivalent in terms of processing difficulty because the quantity of information to be stored and the degree of response conflict was held constant across tasks. That is, the strength of executive function interference was roughly equal across tasks, but the duration of the interference was greater in the continuous than in the temporary condition. In support of this point, participants performed equally well on the temporary and continuous concurrent tasks. Although not likely in light of the equivalent performance, it is possible that the continuous task resulted in greater processing difficulty because the digits were stored for $1 \mathrm{~s}$ more than in the temporary task (i.e., through the intertrial interval; digits were stored for approximately 7 vs. 8 s). Perhaps, then, the difference in strategy use between II-temporary and II-continuous conditions was due to the processing difficulty associated with the concurrent task, rather than the fact that executive functions were never available. If this were the case, then other studies which have manipulated the processing difficulty of the concurrent task should also find that the more difficult task caused greater interference for II learning. However, Miles and Minda (2011, Experiment 2) found that a very easy concurrent task (identifying whether a dot was red) and a more difficult concurrent task (identifying whether the current red dot was previously red) interfered equally with II learning. Therefore, even if the temporary and continuous tasks used in the present study did differ in terms of processing difficulty, it is not likely that this difference affected II learning. Instead, it is more likely that the fact that executive functions were never available was the driving factor behind the differences seen in categorization.

Given that executive functions are known to be important for the verbal system, it may be reasonable to expect that continuously taxing executive functions would have a greater effect on RD categorization than would temporarily taxing executive functions. However, our study showed that these tasks did not significantly differ in their effect on RD learning. Our failure to find an effect of concurrent task type on RD performance and strategy use may illustrate that the duration of executive function interference is not an important factor in the operation of the verbal system. The verbal system requires executive functions during the categorization trial to recall the categorization rule, inhibit responses based on irrelevant dimensions, and process feedback. However, executive functions likely have less of a role to play between categorization trials, and as a result, continuously taxing executive functions may not be particularly detrimental to the verbal system, relative to taxing executive functions only during the categorization trial. Instead, manipulating the strength (e.g., number of items to be remembered), rather than the duration (i.e., whether executive functions are available during the intertrial interval), of the executive function interference may affect the verbal system by further decreasing the system's ability to find and apply the categorization rule, inhibit responses, and process feedback.

Single or multiple category-learning systems

The present study has been interpreted under the assumption of multiple category-learning systems, but instead, one could assume a single category-learning system that is able to learn RD and II category sets using a 
single set of cognitive resources (see, e.g., Newell et al., 2011). On their own, the performance data from this experiment do not provide evidence against a single system account of category learning. The RD and the II category sets were similarly affected by the temporary and continuous tasks, potentially providing evidence for a single categorization system that is reliant on working memory and executive functions. However, a singlesystem account cannot explain the pattern of strategy use seen across the two category sets. Without appealing to multiple systems, it is difficult to parsimoniously explain the differential effect of temporary and continuous tasks on appropriate strategy use for the two category sets. Specifically, the effect of the temporary task would be expected to be similar for both types of categories, which it was not. Especially if one considers that the II category set was more difficult and required attention to two dimensions, it is difficult to explain why appropriate strategy use for this category set was less, rather than more, susceptible to the temporary task than was the simpler RD category set. Therefore, when the performance and strategy data are considered together, these data offer support for multiple categorization systems. For the verbal system, taxing executive functions continuously may be no more detrimental to learning than taxing them temporarily. For the nonverbal system, continuously taxing executive functions is particularly detrimental because this fully restricts access to executive functions, which possibly interferes with the transition to the nonverbal system.

Our and other recent research (e.g., Huang-Pollock et al., 2011; Maddox et al., 2009, 2010; Schnyer et al., 2009) necessitates that the original description of the category-learning systems be updated. The nonverbal system was initially thought to operate independently of executive functions (Ashby et al., 1998; Minda \& Miles, 2010), but it is becoming more clear that executive functions do play a role in nonverbal categorization, likely in aiding the transition away from the verbal system. By postulating that both systems are reliant on executive functions, albeit for different purposes, it is possible that the category-learning systems are not as different as was initially thought. In some sense, proponents of a single category-learning system and proponents of multiple category-learning systems may not be that divergent, in that both groups agree that there is some overlap in the cognitive resources used for learning information integration and ruledefined category sets.

In one version of the single-system account, RD and II categories may be learned using a single category learning system, but this system may need to implement different strategies to learn each type of category. Under such a framework, a verbal, single-dimensional strategy may be dominant, and executive functions may be needed to transition away from the dominant strategy and to a nonverbal, II strategy. Strictly speaking, this could be a single-system account but has many similarities with a multiple-systems framework because different cognitive processes may be important for implementing each type of strategy. Although there is convincing evidence (e.g., Maddox \& Filoteo, 2001; Nomura et al., 2007; Nomura \& Reber, 2012) that these strategies are subserved by distinct neurobiological systems, this is not the focus of the present article, nor is it an especially important point for the present findings. Instead, the important point is that there are multiple approaches for learning new categories and executive functions may be important for mediating the transition between these approaches, regardless of whether they are construed as separate systems, strategies, or otherwise.

\section{Conclusions}

This study illustrates that continuously taxing executive functions has a different effect on the nonverbal system than does temporarily taxing executive functions. When executive functions were never fully available, the II category set was less likely to be learned using the appropriate strategy, suggesting that continuously taxing executive functions interferes with the transition to the nonverbal system. For the verbal system, temporary and continuous taxation of executive functions did not differentially affect categorization performance or strategy use, suggesting that the duration of executive function taxation is not an important factor for the nonverbal system. This study illustrates that executive functions play an important but different role in each of the category-learning systems. For the verbal system, executive functions are used during the categorization trial to support hypothesis testing and process feedback. For the nonverbal system, executive functions may be used to facilitate the transition from the dominant verbal system to the nonverbal system. These results also provide more general insight into how multiple cognitive systems may interact during complex cognitive tasks.

\section{Appendix 1}

For the model-based strategy analysis, we adopted the assumptions and model-based analysis methods of GRT. First, we assumed that a participant categorizes stimuli by partitioning his or her perceptual space into two regions. This partition is known as a decision bound. 
The participant categorizes each stimulus according to the region in which it falls. That is, given a stimulus $i$ and the decision bound function $h_{\left(x_{i}\right)}$, the categorization decision can be described as "Respond A if $h_{\left(x_{i}\right)}>0$, and respond B otherwise".

Second, on the basis of GRT, we assumed that perception of a stimulus is subject to noise (i.e., perceptual noise; $e_{p}$ ), so that repeated exposures of the same stimulus do not always yield the same perceptual effect. The perceived coordinate of the stimulus $i$ is denoted as $x_{i}$, and its distribution is multivariate normal. This assumption makes the response to a stimulus probabilistic. The probability of responding $\mathrm{A}$ to $x_{i}$ is

$P\left(A \mid x_{i}\right)=P\left[h_{\left(x_{i}\right)}>0 \mid x_{i}\right]$.

In the present application, the decision bounds are assumed to be linear and can be written as:

$h\left(x_{i}\right)=b^{T} x_{i}+c+\epsilon$,

where $b$ represents a vector of constants and $c$ represents some scalar. The variable $\in$ denotes random noise with zero mean and variance $\sigma_{\epsilon}^{2}$, representing criterial noise (i.e., noise in the participant's memory of the decision bound). Thus, the mean and variance of $h\left(x_{i}\right)$ are $b^{T} x_{i}+c$ and $b^{T} \Sigma b+\sigma_{\epsilon}^{2}$, respectively. Because the distribution of $x_{i}$ is multivariate normal and the distribution of $e_{c}$ is assumed to be normal, the probability of responding A to $x_{i}$ becomes

$P(A \mid x)=\Phi\left(\frac{b^{T} x_{i}+c}{\sqrt{b^{T} \Sigma b+\sigma_{\epsilon}^{2}}}\right)$,

where $\Phi(\cdot)$ is the cumulative distribution function of the standard normal distribution.

With these assumptions in place, we attempted to find the configuration of the decision bound that best describes each participant's categorization behavior in each block of trials. The stimuli in the present study can be represented in two dimensions - that is, frequency and orientation. Different configurations of the decision bound can be interpreted as different categorization strategies. In particular, when the slope of the decision bound is zero or undefined, the participant attended to only one of the dimensions for categorization. When the slope is defined and nonzero, the participant attended to and integrated the information from both dimensions. By changing the number of parameters that can vary freely, we can fit several different decision bound models that correspond to three classes of strategies (frequency, orientation, II).
Two frequency strategies were fit to participants' responses. In one, the intercept of the decision bound and the noise parameter were allowed to vary. In the second, the intercept was set to the optimal value, and the noise parameter was allowed to vary. A single orientation strategy was used, in which the intercept and noise parameter were allowed to vary. Four II strategies were used. In one, the slope, intercept, and noise parameters were allowed to vary. In the second, the slope and the noise parameter were allowed to vary, but the intercept was set at the optimal value. In the third, the intercept and the noise parameter were allowed to vary, but the slope was set at the optimal value. Finally, the noise parameter was allowed to vary, and the slope and intercept were set to optimal values.

In addition to the decision-bound-based strategies, we also fit models where the classification decision is based on random guessing. One of the models assumed that participants randomly responded $\mathrm{A}$ or $\mathrm{B}$ with an equal probability for each response (i.e., $P\left(A \mid x_{i}\right)=P\left(B \mid x_{i}\right)=.5$ ). This model had no free parameters. The other model assumed that participants randomly responded A or B with unequal probability for each response. This model had one free parameter, the probability of responding A.

The free parameters for each model were estimated by the maximum likelihood method. The likelihood of observing a given set of response patterns, $r=\left(r_{1}, \ldots, r_{n}\right)$, is

$L(r)=\prod_{i=1}^{n} P\left(A \mid x_{i}\right)^{r_{i} *} P\left(B \mid x_{i}\right)^{1-r_{i}}$,

where $r_{i}=1$ if response A was made to $x_{i}$ and $r_{i}=0$ if response $\mathrm{B}$ was made. The relative fit of the models was compared using AIC:

$A I C=-2 * \log (L(r))+2 d f$,

where $d f$ is the number of free parameters in the model. AIC is a measure of goodness of fit that takes into account the number of free parameters in the model. Because AIC is a measure of goodness of fit, small values indicate a good fit of the strategy to the data.

Absolute model fit was measured using root mean square deviation (RMSD). For each participant, we determined the best-fitting model during the final block and calculated the RMSD as follows:

$R M S D=\sqrt{\frac{\sum_{i=1}^{n}\left(r_{i}-P\left(A \mid x_{i}\right)\right)^{2}}{n}}$.

Table 4 in Appendix 2 illustrates the average RMSD for participants in each condition who were best fit by each type of strategy. 


\section{Appendix 2}

Table 4 Block 4 root mean square deviation of participants in each condition who were best fit by each categorization strategy

\begin{tabular}{|c|c|c|c|c|}
\hline & \multicolumn{4}{|l|}{ Strategy } \\
\hline & $\begin{array}{l}\text { Information Integration } \\
M(S D)\end{array}$ & $\begin{array}{l}\text { Frequency } \\
M(S D)\end{array}$ & $\begin{array}{l}\text { Orientation } \\
M(S D)\end{array}$ & $\begin{array}{l}\text { Guess } \\
M(S D)\end{array}$ \\
\hline \multicolumn{5}{|c|}{ Information Integration } \\
\hline Control & $.44(.08)$ & $.45(.10)$ & - & - \\
\hline Temporary & $.46(.11)$ & $.48(.06)$ & - & $.42(.12)$ \\
\hline Continuous & $.46(.07)$ & $.49(.07)$ & - & $.48(.03)$ \\
\hline \multicolumn{5}{|l|}{ Rule-defined } \\
\hline Control & $.30(.08)$ & $.40(.11)$ & - & - \\
\hline Temporary & $.55(.17)$ & $.37(.12)$ & - & $.48(.02)$ \\
\hline Continuous & $.46(.12)$ & $.40(.10)$ & - & $.46(.05)$ \\
\hline
\end{tabular}

Note. A blank cell indicates that no participant was best fit by that strategy in the corresponding condition

\section{References}

Ashby, F. G. (1992). Multidimensional models of categorization. In F. G. Ashby (Ed.), Multidimensional models of perception and cognition (pp. 449-483). Hillsdale, NJ: Earlbaum.

Ashby, F. G., Alfonso-Reese, L. A., Turken, A. U., \& Waldron, E. M. (1998). A neuropsychological theory of multiple systems in category learning. Psychological Review, 105, 442-481.

Ashby, F. G., \& Crossley, M. J. (2010). Interactions between declarative and procedural-learning categorization systems. Neurobiology of Learning and Memory, 94, 1-12.

Ashby, F. G., \& Gott, R. E. (1988). Decision rules in the perception and categorization of multidimensional stimuli. Journal of Experimental Psychology: Learning, Memory, \& Cognition, 14, 33-53.

Ashby, F. G., \& Maddox, W. T. (2005). Human category learning. Annual Reviews in Psychology, 56, 149-178.

Ashby, F. G., Maddox, W. T., \& Bohil, C. J. (2002). Observational versus feedback training in rule-based and information-integration category learning. Memory \& Cognition, 30, 666-677.

Ashby, F. G., \& O’Brien, J. (2005). Category learning and multiple memory systems. Trends in Cognitive Sciences, 9, 83-89.

Ashby, F. G., \& Valentin, V. V. (2005). Multiple systems of perceptual category learning: Theory and cogntive tests. In H. Cohen \& C. Lefebvre (Eds.), Categorization in Cognitive Science Categorization in cognitive science (pp. 16-30). New York, NY: Elsevier.

Buckner, R. L. (2004). Memory and executive function in aging and AD: Multiple factors that cause decline and reserve factors that compensate. Neuron, 44, 195-208.

Bunge, S., \& Zelazo, P. (2006). A brain-based account of the development of rule use in childhood. Current Directions in Psychological Science, 15, 118-121.

Casey, B. J., Giedd, J. N., \& Thomas, K. M. (2000). Structural and functional brain development and its relation to cognitive development. Biological Psychology, 54, 241-257.

Decaro, M. S., Carlson, K. D., Thomas, R. D., \& Beilock, S. L. (2009). When and how less is more: Reply to Tharp and Pickering. Cognition, 111, 397-403.

Decaro, M. S., Thomas, R. D., Albert, N. B., \& Beilock, S. L. (2011). Choking under pressure: Multiple routes to skill failure. Journal of Experimental Psychology: General, 140, 390-406.
Erickson, M. A. (2008). Executive attention and task switching in category learning: Evidence for stimulus dependent representation. Memory \& Cognition, 36, 749-761.

Filoteo, J. V., Lauritzen, J. S., \& Maddox, W. T. (2010). Removing the frontal lobes: The effects of engaging executive functions on perceptual category learning. Psychological Science, 21, 415-423.

Fisk, J. E., \& Sharp, C. A. (2004). Age-Related impairment in executive functioning: Updating, inhibition, shifting, and access. Journal of Clinical and Experimental Neuropsychology, 26, 874-890.

Friedman, N. P., Miyake, A., Corley, R. P., Young, S. E., DeFries, J. C., \& Hewitt, J. K. (2006). Not all executive functions are related to intelligence. Psychological Science, 17, 172-179.

Harrison, Y., Horne, J. A., \& Rothwell, A. (2000). Prefrontal neuropsychological effects of sleep deprivation in young adults-a model for healthy aging? Sleep, 23, 1067-1073.

Helie, S., Waldschmidt, J. G., \& Ashby, F. G. (2010). Automaticity in rule-based and information-integration categorization. Attention, Perception, \& Psychophysics, 72, 1013-1031.

Huang-Pollock, C. L., Maddox, W. T., \& Karalunas, S. L. (2011). Development of implicit and explicit category learning. Journal of Experimental Child Psychology, 109, 321-335.

Lamberts, K. F., Evans, J. J., \& Spikman, J. M. (2010). A real-life, ecologically valid test of executive functioning: The executive secretarial task. Journal of Clinical and Experimental Neuropsychology, 32, 56-65.

Maddox, W. T., \& Ashby, F. G. (1993). Comparing decision bound and exemplar models of categorization. Perception and Psychophysics, 53, 49-70.

Maddox, W. T., Ashby, F. G., \& Bohil, C. J. (2003). Delayed feedback effects on rule-based and information-integration category learning. Journal of Experimental Psychology: Learning, Memory, \& Cognition, 29,650-662.

Maddox, W. T., Ashby, F. G., Ing, A. D., \& Pickering, A. D. (2004a). Disrupting feedback processing interferes with rule-based but not information-integration category learning. Memory \& Cognition, 32, 582-591.

Maddox, W. T., Bohil, C. J., \& Ing, A. D. (2004b). Evidence for a procedural-learning based system in perceptual category learning. Psychonomic Bulletin \& Review, 11, 945-952.

Maddox, W. T., \& Filoteo, J. V. (2001). Striatal contributions to category learning: Quantitative modeling of simple linear and complex rule learning in patients with Parkinson's disease. Journal of the International Neuropsychological Society, 7, 710-727. 
Maddox, W. T., Filoteo, J. V., Hejl, K. D., \& Ing, A. D. (2004c). Category number impacts rule-based but not information-integration category learning: Further evidence for dissociable category-learning systems. Journal of Experimental Psychology: Learning, Memory, \& Cognition, 30, 227-245.

Maddox, W. T., Glass, B. D., Wolosin, S. M., Savarie, Z. R., Bowen, C., \& Matthews, M. D. (2009). The effects of sleep deprivation on informationintegration categorization performance. Sleep, 32, 1439-1449.

Maddox, W. T., \& Ing, A. D. (2005). Delayed feedback disrupts the procedural-learning system but not the hypothesis-testing system in perceptual category learning. Journal of Experimental Psychology: Learning, Memory, \& Cognition, 31, 100-107.

Maddox, W. T., Love, B. C., Glass, B. D., \& Filoteo, J. V. (2008). When more is less: Feedback effects in perceptual category learning. Cognition, 108, 578-589.

Maddox, W. T., Pacheco, J., Reeves, M., Zhu, B., \& Schnyer, D. M. (2010). Rule-based and information-integration category learning in normal aging. Neuropsychologia, 48, 2998-3008.

Markman, A. B., Maddox, W. T., \& Worthy, D. A. (2006). Choking and excelling under pressure. Psychological Science, 17, 944-948.

Miles, S. J., \& Minda, J. P. (2011). The effects of concurrent verbal and visual tasks on category learning. Journal of Experimental Psychology: Learning, Memory, \& Cognition, 37, 588-607.

Minda, J. P., Desroches, A. S., \& Church, B. A. (2008). Learning ruledescribed and non-rule-described categories: A comparison of children and adults. Journal of Experimental Psychology: Learning, Memory, \& Cognition, 34, 1518-1533.

Minda, J. P., \& Miles, S. J. (2010). The influence of verbal and nonverbal processing on category learning. In B. H. Ross (Ed.), The psychology of learning and motivation the psychology of learning and motivation (Vol. 52, pp. 117-162). Burlington: Academic Press.

Miyake, A., Friedman, N. P., Emerson, M. J., Witzki, A. H., \& Howerter, A. (2000). The unity and diversity of executive functions and their contributions to complex "frontal lobe" tasks: A latent variable analysis. Cognitive Psychology, 41, 49-100.
Newell, B. R., Dunn, J. C., \& Kalish, M. (2011). Systems of category learning: Fact or fantasy? In B. H. Ross (Ed.), The psychology of learning and motivation the psychology of learning and motivation (Vol. 54, pp. 167-215). Burlington: Elsevier Inc.

Nilsson, J. P., Söderström, M., Karlsson, A., Lekander, M., Kerstedt, T. A., \& Lindroth, N. (2005). Less effective executive functioning after one night's sleep deprivation. Journal of Sleep Research, 14, 51-56.

Nomura, E. M., Maddox, W. T., Filoteo, J. V., Ing, A. D., Gitelman, D. R., \& Parrish, T. B. (2007). Neural correlates of rule-based and informationintegration visual category learning. Cerebral Cortex, 17, 37-43.

Nomura, E. M., \& Reber, P. J. (2008). A review of medial temporal lobe and caudate contributions to visual category learning. Neuroscience and Biobehavioral Reviews, 32, 279-291.

Nomura, E. M., \& Reber, P. J. (2012). Combining computational modeling and neuroimaging to examine multiple category learning systems in the brain. Brain Sciences, 2, 176-202.

R Core Team. (2012). R: A language and environment for statistical computing [Manuel de logiciel]. Vienna, Austria.

Rehder, B., \& Hoffman, A. B. (2005). Eyetracking and selective attention in category learning. Cognitive Psychology, 51, 1-41.

Schnyer, D. M., Maddox, W. T., Ell, S. W., Davis, S., Pacheco, J., \& Verfaellie, M. (2009). Prefrontal contributions to rule-based and information-integration category learning. Neuropsychologia, 47, 2995-3006.

Waldron, E. M., \& Ashby, F. G. (2001). The effects of concurrent task interference on category learning: Evidence for multiple category learning systems. Psychonomic Bulletin \& Review, 8, 168-176.

Worthy, D. A., Maddox, W. T., \& Markman, A. B. (2009). Less is more: Stimulus-feedback co-occurrence in perceptual category learning. Proceedings of the Cognitive Science Society, 1-6.

Zeithamova, D., \& Maddox, W. T. (2006). Dual-task interference in perceptual category learning. Memory \& Cognition, 34, 387-398.

Zeithamova, D., \& Maddox, W. T. (2007). The role of visuospatial and verbal working memory in perceptual category learning. Memory \& Cognition, 35, 1380-1398. 